\title{
Extreme diel horizontal migrations by a tropical nearshore resident micronekton community
}

\author{
Kelly J. Benoit-Bird ${ }^{1,2, *}$, Whitlow W. L. $\mathrm{Au}^{2}$ \\ ${ }^{1}$ College of Oceanic and Atmospheric Sciences, Oregon State University, 104 COAS Administration Building, Corvallis, \\ Oregon 97331, USA \\ ${ }^{2}$ Hawaii Institute of Marine Biology, University of Hawaii, PO Box 1106, Kailua, Hawaii 96734, USA
}

\begin{abstract}
The mesopelagic boundary community around the Hawaiian Islands is a land-associated, sound-scattering layer that undergoes diel migrations with both a vertical and horizontal component. To understand horizontal migration, it is important to understand the full cycle of migration and to determine which animals undertake these movements and which do not. We developed a video camera system to quantitatively examine the numerical density, size, and taxonomic composition of micronekton. We combined the camera system with vessel-mounted echosounders to document the full migration range of micronekton and describe the changes in composition and density throughout their diel migration. Onshore horizontal movement is limited to waters deeper than $23 \mathrm{~m}$. Offshore, horizontal migration seems to cease between 9 and $11 \mathrm{~km}$ from the shoreline. Some animals in the mesopelagic boundary community undertake horizontal migrations of at least $11 \mathrm{~km}$ roundtrip each night. This impressive migration indicates that there must be a substantial benefit to horizontal migration. The migrating animals split into multiple, distinct layers at night with differences in micronekton density, composition, and size. Myctophid fishes are the most abundant component of the horizontally migrating layers. Large myctophids are the first to migrate into and last to leave the shallow water areas. During the day, the layers merge into a single layer at $400 \mathrm{~m}$ depth or deeper. At night, there is evidence of strong partitioning of habitat by these animals in space and time, which - along with the high densities of animals suggests that competition is important in driving the behavior of, and structuring, the community.
\end{abstract}

KEY WORDS: Mesopelagic micronekton - Mesopelagic boundary community $\cdot$ Diel migration $\cdot$ Horizontal migration $\cdot$ Myctophidae $\cdot$ Hawaiian Islands

Resale or republication not permitted without written consent of the publisher

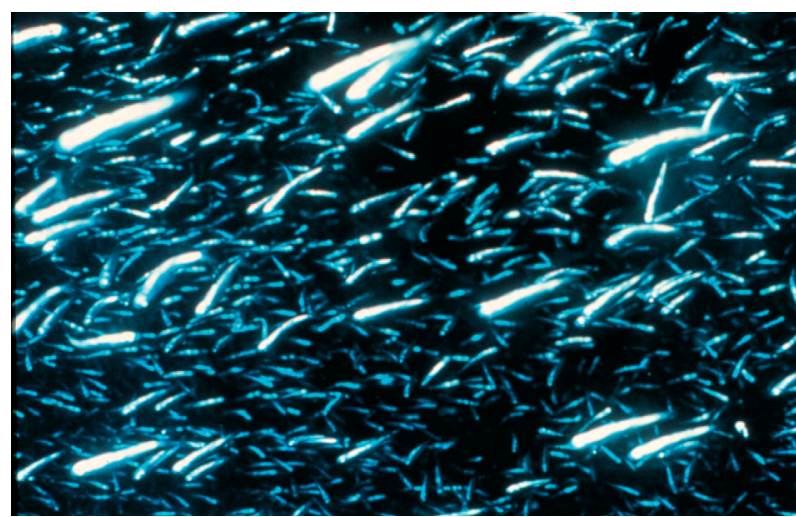

Midwater fishes, shrimp, and squid around the Hawaiian Islands perform daily onshore-offshore migrations of up to $11 \mathrm{~km}$ round-trip each night. Horizontal migration allows the resident micronekton community to remain over the islands' slopes. The photo shows a nighttime aggregation of myctophids in shallow water off Oahu, Hawaii.

Photo taken by ROV (NOAA, National Undersea Research Program)

\section{INTRODUCTION}

Land-associated mesopelagic species have been reported along steep-slope habitats worldwide including Suruga Bay, Japan (Kubota et al. 1982), the Arabian Sea (Gjøsaeter 1984), southwest Africa (Hulley 1992), the northeast Atlantic (Mauchline \& Gordon 1991), Tasmania (May \& Blaber 1989), Indonesia (Kawaguchi \& Shimuzu 1978), and several seamounts (Parin \& Prut'ko 1985, Boehlert \& Genin 1987, Boehlert et al. 1992). In Hawaiian nearshore waters, there is an island-associated community of midwater micronekton, termed the mesopelagic boundary community (Reid et al. 1991). This community, comprised of various spe- 
cies of fishes, shrimps, and squids has a composition unique to the boundary region and is distributed along a narrow band where the upper slopes of the underwater portion of the islands meet the oceanic, mesopelagic environment (Reid et al. 1991). Animals in Hawaii's nearshore, micronekton sound-scattering layer (SSL) attain remarkably high densities, up to 1800 animals $\mathrm{m}^{-3}$ (Benoit-Bird et al. 2001). These animals undergo predictable diel migrations (with both a vertical and horizontal component), moving them to within $1 \mathrm{~km}$ of the shoreline each night into waters shallower than typical mesopelagic habitat (BenoitBird et al. 2001).

Nocturnal horizontal migration of both plankton and consumers into shallow waters has been observed in both freshwater (De Meester 1993, Comeau \& Boisclair 1998, White 1998) and marine systems (Sasaki 1914, Omori \& Ohta 1981, Webb \& Wooldridge 1990, Lindstrom 1991, Suh \& Yu 1996,). It is hypothesized that these horizontal migrations, like the vertical migrations that they often accompany, help organisms find food and avoid predators (White 1998). However, the role of these movements in the life of the migrators and the ecological consequences of these patterns are poorly understood, particularly for animals larger than plankton.

Hawaii's land-associated mesopelagic micronekton provides a direct energy subsidy to the pelagic community, where it serves as an important food resource to billfish (Skillman 1998), tunas (He et al. 1997), and spinner dolphins (Norris \& Dohl 1980, Benoit-Bird \& $\mathrm{Au}$ 2003a). It is also an important component of the deepwater benthic system, where it is consumed by bottomfish (Haight et al. 1993). We have shown that predators of mesopelagic micronekton around the Hawaiian Islands are directly and predictably influenced by the migration dynamics of this SSL because the costs and benefits of foraging change dramatically throughout the migration (Benoit-Bird \& Au 2003a). Recent studies of the SSL have shown that these animals migrate directly over coral reefs (Benoit-Bird \& $\mathrm{Au}$ 2004) potentially transforming nutrients available in these nutrient-limited waters. Mesopelagic micronekton consumes most of the zooplankton production in Hawaii's coastal waters (Clarke 1973), and then moves to deeper, bio-energetically poor waters. Through their diel migration, mesopelagic animals move between 2 systems, the deepwater pelagic waters of their daytime habitat and the shallow, nearshore waters of their nighttime habitat. We suggest that the Hawaiian mesopelagic boundary community provides a fundamental link for energy and nutrient transfer between ecosystems, while being the most important consumer of zooplankton and the most important food for higher trophic levels.
Despite the ecological consequences of the mesopelagic boundary community's diel movement, only a narrow, nearshore component of the diel horizontal migration of micronekton around Hawaii has been described. Limited to depths of $156 \mathrm{~m}$ (Benoit-Bird \& $\mathrm{Au}$ 2001), these studies did not observe the full extent of the migration pattern both offshore and inshore. Further, current observations have focused on the broad pattern of an assemblage, without an understanding of the movements of constituent taxa. To understand the ultimate significance and benefits of horizontal migration, as well as its consequences on the ecosystem, it is important to understand the full cycle of migration and to determine which animals undergo this movement and which do not.

The high mobility of micronektonic animals in the mesopelagic boundary community has made it difficult to assess community composition using traditional techniques like trawling and strobe photography. Trawling for micronekton could provide substantial information on the composition of the mesopelagic boundary community. However, our experience with trawling for these animals suggests that it is not a viable technique for quantitative sampling of these animals: (1) shallow, high-relief areas in nearshore waters near the landward limit of the animals' migration present a serious risk of bottom collisions to the gear; (2) the shallow, relatively well-lit waters into which these mesopelagic animals migrate each night permit a high degree of net avoidance. Any net large enough to effectively sample mobile micronekton $(10 \times 10 \mathrm{~m}$ opening) cannot be towed from a vessel small enough to move into the shallow areas inhabited by the boundary community. Previous attempts to utilize vertically profiling video and still camera systems that required light yielded limited results because of strong avoidance of the lights by micronekton (Benoit-Bird \& Au 2003b). Simultaneous acoustic data revealed that when these profiling camera systems were utilized without light, avoidance was not observed, even $2 \mathrm{~m}$ from the large frame; however, acoustic data alone could not provide information on SSL composition.

The goals of this study were to (1) develop a tool to quantitatively examine the taxonomic composition of micronekton in Hawaii's nearshore SSL, (2) document the full migration range of micronekton in the SSL, and (3) describe the changes in composition and density of mesopelagic animals throughout their diel migration. We subsequently addressed questions about the ecological role of the nearshore SSL in Hawaiian waters, evaluated the potential costs these animals endure each day through their migration, and examined potential partitioning of habitat among the animals in this diverse and dense assemblage. 


\section{MATERIALS AND METHODS}

Camera system. To quantitatively identify micronektonic animals and estimate their size distribution, we used optical imaging. Optical techniques are constrained by the quantity and quality of light used for illumination because of strong avoidance of visible light by micronekton (Benoit-Bird \& Au 2003b). Recent attempts to image deep-sea nekton have employed red light beyond the target species' spectral sensitivity (e.g. Eye-in-the-Sea; Raymond \& Widder 2005). To overcome problems with light avoidance by mesopelagic micronekton, we used a highly sensitive video camera system for identification purposes. The camera system used CCD (charge coupled device) cameras (Remote Ocean Systems Low-Night Navigator with a custom lens) with high light sensitivity $\left(3.4 \times 10^{-4}\right.$ lux $)$. These cameras use infrared rather than visible light for illumination, with a lower likelihood of triggering avoidance (Stone 1998). Two low-light cameras were used in a stereo fashion to allow animals identified in both cameras to be precisely located within the $575 \mathrm{l}$ of the cameras' overlapping fields of view, permitting quantitative density estimates of mesopelagic animals to be made and measurements of their size to be taken (Fig. 1). Measurements of size took into account the apparent length of the animal in both cameras, which allowed their actual length to be determined using basic trigonometric relationships, eliminating the problem of apparent foreshortening from one camera.

The cameras were mounted to an aluminum frame $90^{\circ}$ relative to each other with the center of the lenses $1 \mathrm{~m}$ apart. An infrared (940 nm) LED array (custom built) in a transparent housing was mounted directly below each camera. Each array consisted of 140 LEDs, emitting approximately 5500 lumens at a $60^{\circ}$ radiation angle. Both data and power for the cameras and lights were transmitted by a Kevlar-jacketed multi-conductor cable (manufactured to custom specifications by Falmat) that was also used to lower the system. Video from the 2 cameras was written to digital video discs (DVDs) using stand-alone recorders (Panasonic DMR E-30). This provided the highest resolution recordings and permitted the files to be opened directly on a computer, eliminating any loss of resolution. A pressure sensor on the camera system sent real-time depth information to the surface via the camera cable. In addition, pressure data were converted to electronic signals using a voltage to frequency converter, and recorded to an audio channel of each DVD recorder.

The camera system was calibrated in a seawater tank utilizing small, linear targets to measure the edges of the volume of view, confirming the sampling volume for density estimates. In addition, the width of the field of view of each camera at each point was measured at $5 \mathrm{~cm}$ intervals using a standard grid. These measurements showed that over the size range of 2 to $12 \mathrm{~cm}$, length measurements for an imaged target that is not flexed are within $\pm 5 \%$ of actual length, regardless of relative orientation.

Echosounder surveys. To fully observe the distribution of SSLs over time, we conducted surveys using a 2-frequency, split-beam echosounder system (Simrad EK60s). The $70 \mathrm{kHz}$ echosounder used a $128 \mu$ s pulse, while the $200 \mathrm{kHz}$ echosounder used a $64 \mu$ s pulse. Both systems had a $7^{\circ}$ conical split beam and collected 4 pulses $\mathrm{s}^{-1}$. The system was calibrated using an indi-
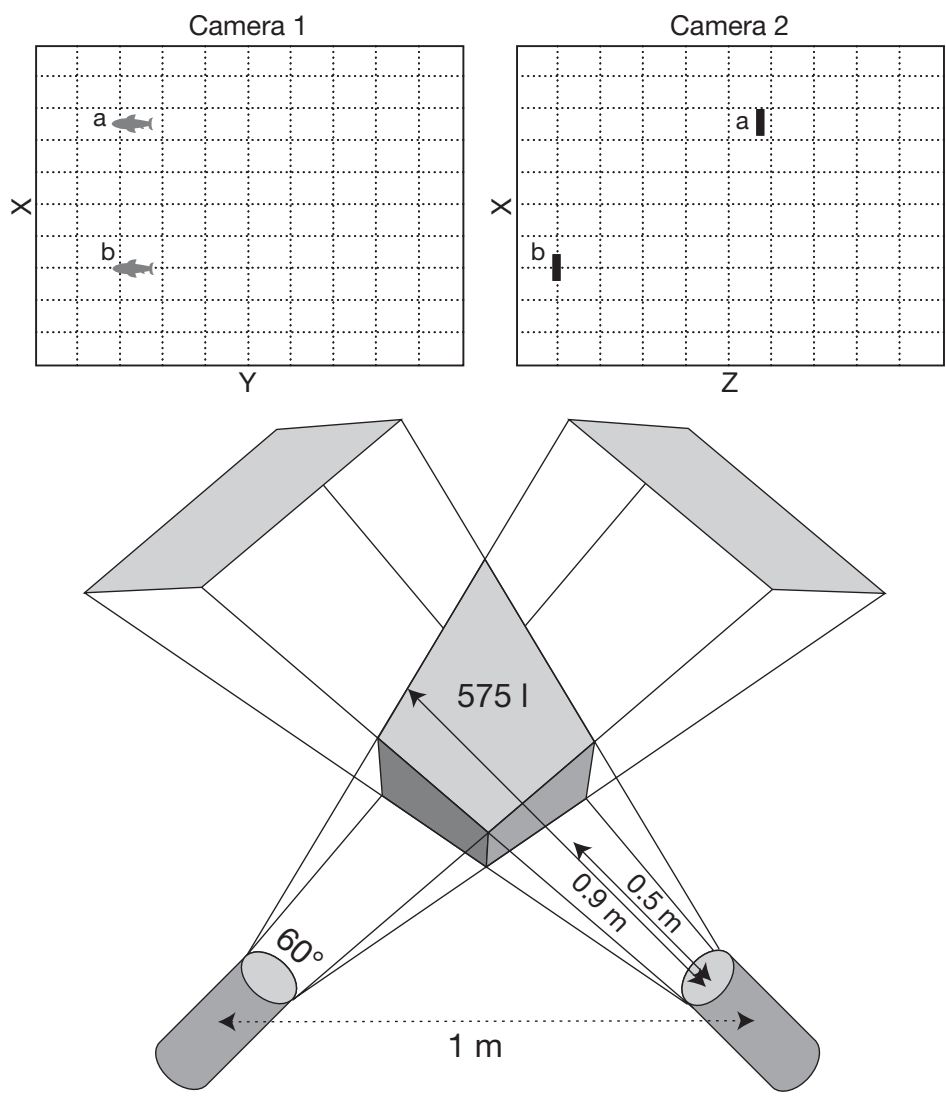

Fig. 1. Micronekton stereo camera system. The system uses light sensitive cameras to allow identification of animals, measurement of their size, and quantitative assessment of their density. Views of 2 'fish' captured in the volume where the views of the 2 cameras cross. A simple coordinate system has been drawn on the views to show an example of the process of data analysis. In the view from camera 1, 2 fish of apparently the same length can be seen at the same $y$-position. In the view from camera 2, the 2 fish are at different $z$ coordinates with fish (a) being much further from the camera than fish (b). Fish (b) is thus much smaller than fish (a). By measuring the coordinates of each fish, its apparent length, and the width of each camera's field of view at those coordinates, the length of the fish can be estimated 
rect procedure incorporating a $38.1 \mathrm{~mm}$ diameter tungsten carbide reference sphere, as prescribed by Foote et al. (1987).

Sampling design. Extensive surveys of the micronekton SSLs were conducted off the leeward coast of Oahu, Hawaii $\left(21^{\circ} 32.21^{\prime} \mathrm{N}, 158^{\circ} 14.38^{\prime} \mathrm{W}\right.$; $21^{\circ} 28.78^{\prime} \mathrm{N}$, $158^{\circ} 14.55^{\prime} \mathrm{W} ; 2^{\circ} 32.40^{\prime} \mathrm{N}, 158^{\circ} 20.13^{\prime} \mathrm{W} ; 21^{\circ} 28.94^{\prime} \mathrm{N}$, $158^{\circ} 20.24^{\prime} \mathrm{W}$ ) over $12 \mathrm{~d}$ (each $13 \mathrm{~h}$ long) between May 12 and June 8, and August 20 and 25, 2004. Echosounder surveys were conducted to determine the distribution as a function of time and space of (1) the SSL (the boundary community as a whole), (2) distinct individual layers separated in space from other scatterers, and (3) strata, or distinct horizontal bands within individual layers. Transects ran perpendicular to the direction of the micronekton migration, to obtain the greatest statistical power to characterize this movement. Surveys covered 8 transects (5 km in length) along the island's slope; the first transect was located $1 \mathrm{~km}$ from the shoreline and subsequent transects were located $2,3,4,5,7,9$, and $11 \mathrm{~km}$ from the shoreline (Fig. 2). The order of transect surveying was randomized in a complete block design with 5 transects, each with 2 vertical profiles, conducted each sampling day. Transects were surveyed at a speed of 5 knots $\left(9.3 \mathrm{~km} \mathrm{~h}^{-1}\right)$ for $1 \mathrm{~h}$, every $3 \mathrm{~h}$ to cover all $24 \mathrm{~h}$ of the day. The orientation and separation of transects permitted the observation of the horizontal components of the boundary community's migration at a large spatial scale. In the hours between surveys of these transects, additional surveys were conducted perpendicular to shore to help integrate data from the parallel transects.

During the alongshore transect surveys, the camera system was used to vertically profile the water column to obtain information on taxonomic composition, animal density, and size. Vertical profiles from the surface to the bottom of the layer-or $600 \mathrm{~m}$, whichever was less-were conducted at 2 locations along each transect (Fig. 2). The location of the first profile was randomly selected while the second was conducted $2.5 \mathrm{~km}$ from the first. The camera was dropped at a rate of 15 to $20 \mathrm{~m} \mathrm{~min}^{-1}$ until it was $5 \mathrm{~m}$ above the top edge of the SSL identified acoustically; then, it was allowed to descend through the layer at 2 to $4 \mathrm{~m} \mathrm{~min}^{-1}$, pulled up to $5 \mathrm{~m}$ above the layer, and allowed to descend again for a total of 3 profiles on each drop. Echosounding was conducted during profiling to observe the camera frame and the SSL surrounding it.

Surveys were also conducted to define the landward edge of the SSL. Between 23:00 and 01:00 h on 3 d during the sampling period, a series of 'sawtooth' transects were surveyed from $1.5 \mathrm{~km}$ from shore shoreward until the water depth reached $6 \mathrm{~m}$. Camera profiles were conducted along each offshore segment of the transect at the nearest to shore point where a SSL was detected.

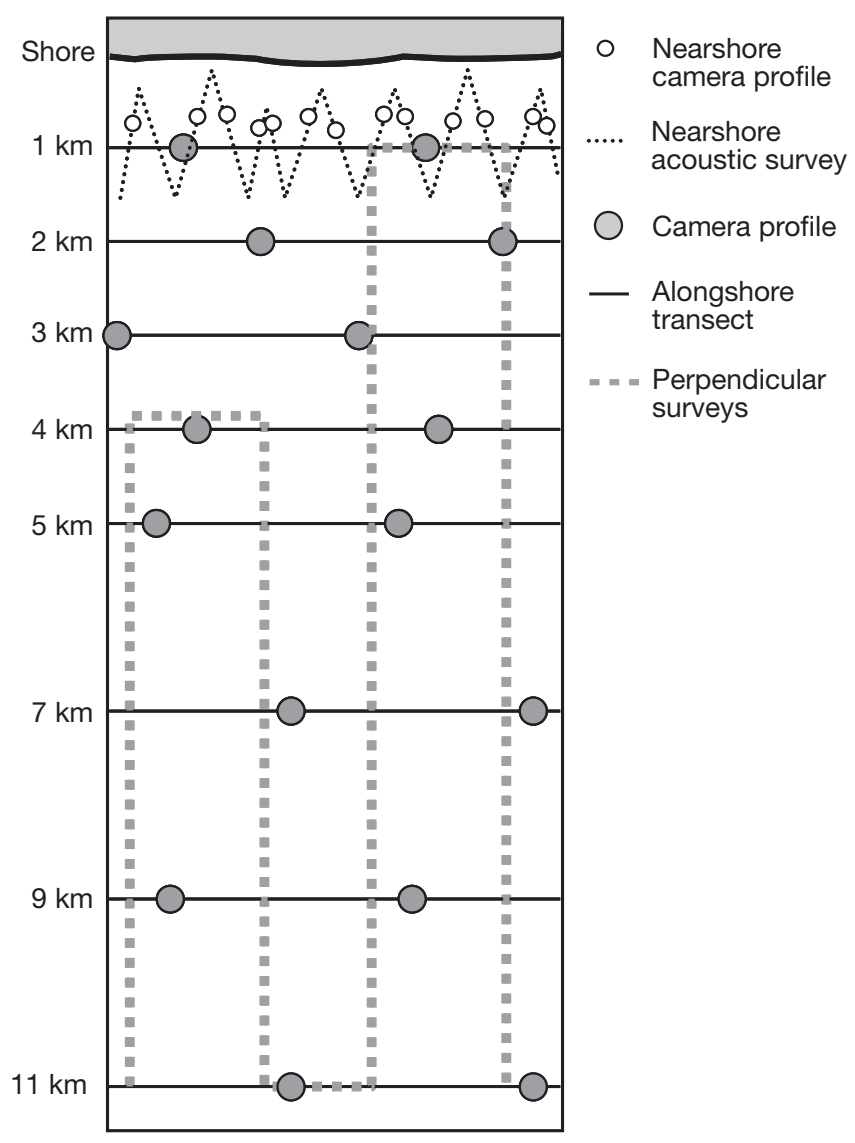

Fig. 2. Sampling design for the acoustic transects and vertical profiles off leeward Oahu, Hawaii. Sampling was conducted along 8 alongshore transects, each $5 \mathrm{~km}$ in length. Along each transect, 2 vertical profiles from the surface to the bottom of the layer, or to $600 \mathrm{~m}$ depth were carried out with the video camera system. Each planned transect was repeated at 12:00, $15: 00,18: 00,21: 00,00: 00,03: 00,06: 00$, and 09:00 h local time. In the hours between these transects, surveys were conducted perpendicular to the shore to help integrate data from the parallel transects. On 3 nights, sawtooth transects were surveyed acoustically to observe the nearshore edge of the sound-scattering layer (SSL). A sample from 1 night's survey is shown

Data analysis. Camera system: Video data for identification of shrimp and fish was analyzed by extracting still views every $0.25 \mathrm{~m}$ from each of the 2 cameras. The radius of the overlapping field of view was a maximum of $0.5 \mathrm{~m}$, limiting possible double counting of animals. Animals seen in still views from both cameras were identified to the lowest taxonomic level possible, providing taxonomically-specific density measures in the quantifiable field of view. The coordinates of the identified animal and the apparent length of the individual were used to estimate its size. Measurements of size take into account the apparent length of the animal in both cameras which allows their actual length to be determined using basic trigonometric relationships, eliminating the problem of apparent foreshortening 
from one camera. Analysis of video data for squid abundance could not be made from extracted images due to the rapid swimming speeds of these animals causing blurring in still images. We observed 15 min of moving video surrounding each extracted still frame; squid could easily be seen in these moving images, and those identified simultaneously in both cameras were used to estimate squid density. Custom imageanalysis software automatically aligned the 2 videos based on their time stamps. The software flagged all images that it calculated to be at least $1.5 \mathrm{~cm}$ in any one dimension, and the extreme edges of the longest dimension were marked. Flagged images were then visually analyzed to identify the target and determine if marked animal edges were accurate. The $\mathrm{x}$ - or vertical position (see Fig. 1) of targets in both images were compared to determine if an individual was observed by both cameras. Simple button selection of the identity of each target in the software automatically logged identity and calculated animal length to a spreadsheet. Data was averaged in $1 \mathrm{~m}$ depth bins from each of the 3 replicate casts to provide adequate sample sizes, given the small sampling volume.

Echosounder surveys: These were used to characterize the vertical extent, density, and horizontal distribution of SSLs (see Benoit-Bird \& Au 2003c, BenoitBird et al. 2001). Echo energy integration approaches were utilized to estimate numerical density of micronekton for comparison with direct measurements of density made with the camera system. For these measurements, scattering from large, individual targets identified with the split-beam echosounder, likely predators on the SSL, was removed.

In situ measurements of target strengths of individually ensonified micronekton were made using the splitbeam echosounder whenever target density and separation permitted. The number of targets per acoustic reverberation volume for each frequency was determined for each pulse and any values that excluded 1 were not included in the analysis (Sawada et al. 1993). This means that at a depth of $10 \mathrm{~m}$, numerical densities could not exceed 3 animals $\mathrm{m}^{-3}$ for $70 \mathrm{kHz}$ measurements and $6 \mathrm{~m}^{-3}$ for $200 \mathrm{kHz}$ measurements. At $100 \mathrm{~m}$, the maximum densities could not exceed 0.13 and 0.26 animals $\mathrm{m}^{-3}$ for 70 and $200 \mathrm{kHz}$ measurements, respectively. At $500 \mathrm{~m}$ where only the $70 \mathrm{kHz}$ system returned results, single targets could only be measured when densities were below 0.0052 animals $\mathrm{m}^{-3}$. These density values were within the ranges observed in the layers, though often far from the mean observed densities, meaning that the sample sizes are low. The single target measurements were compared with the expected target strengths for the animals identified by the camera system. Numerical density of micronektonic animals was calculated from volume scattering using an echo energy integration technique which divides the total backscattered energy by the average backscatter energy from an individual animal to estimate the number of animals per unit volume sampled (MacLennan \& Simmonds 1992). The in situ individual target strengths for each transect were utilized in this analysis.

Avoidance estimation: The taxonomic identification, size, and numeric density information $\left(\mathrm{n} \mathrm{m}^{-3}\right)$ obtained from the camera were combined with measurements of backscattering from individual micronekton (BenoitBird \& $\mathrm{Au} 2001)$ to predict the volume scattering $\left(\mathrm{S}_{\mathrm{v}}\right)$ that would be expected by an echosounder at that location:

$$
S_{V}=\sum_{i=1}^{N}\left(\mathrm{TS}_{i}-10 \log _{10} \frac{n_{i}}{\mathrm{~m}^{3}}\right)
$$

where $\mathrm{TS}_{i}$ is the mean target strength of the $i$-th class of organisms (e.g. 6 to $7 \mathrm{~cm}$ long myctophids) in a given volume or in a unit volume, where $i=1,2 \ldots N$. Target strength was estimated from equations derived from experimental studies: TS $=20 \log L-58.8$ for myctophids, TS $=18.8 \log L-61.7$ for squid, and TS $=19.4 \log$ $L-74.1$ for shrimp at $200 \mathrm{kHz}$, where animal length $(L)$ is in $\mathrm{cm}$ (Benoit-Bird \& $\mathrm{Au} 2001$ ). The TS at $70 \mathrm{kHz}$ was estimated by applying the differences in individual target strength measurements from the 2 echosounders made simultaneously on the same individually identified targets. These differences in paired measurements were comparable to the differences in the slope between the 2 frequencies for mean myctophid length and mean individual target strength, with the target strength at $70 \mathrm{kHz}$ being about $2.25 \mathrm{~dB}$ higher than the target strength at $200 \mathrm{kHz}$ (see Fig. 8). The identity of animals, their length $(L)$, and their density $\left(\mathrm{n} \mathrm{m}^{-3}\right)$ were obtained from the video record. The predictions were compared with scattering measured with split-beam echosounders at 70 and $200 \mathrm{kHz}$. The scattering predictions assisted in the interpretation of the echosounder surveys, while the surveys placed the smallscale information obtained with the camera system into a larger context. Comparisons of these predictions with measured scattering allowed us to evaluate potential avoidance behavior. If avoidance was occurring, we expected that both the scattering predictions and measures of volume scattering from the echosounder would be consistently lower in the area sampled by the camera system than the volume scattering in surrounding areas.

Vertical stratification: To look at vertical stratification in the volume scattering, acoustically estimated density, individual target strengths, proportion of myctophids, and mean size of myctophids in the scatteringlayer strength, a single-factor ANOVA with $1 \mathrm{~m}$ depth bin as the factor was used. For these analyses, all images of animals in the cameras were used to increase the potential sample size. After a significant effect was 
found, Tukey's multiple-range statistic was used to determine which depth bins were homogeneous with neighboring depth bins $(p>0.20)$ and which were significantly different $(\mathrm{p}<0.05)$. Adjacent $1 \mathrm{~m}$ bins that were not significantly different from each other, but were significantly different from depth bins surrounding the homogenous region, were considered to be a stratum with the SSL, as in Benoit-Bird \& Au (2003a).

\section{RESULTS}

\section{Camera system}

The camera system was effectively used to image micronekton to a depth of $600 \mathrm{~m} ; 128$ casts, each consisting of 3 vertical profiles through the SSL, resulted in more than $200 \mathrm{~h}$ of video data and thousands of images of micronekton. The highly aggregated nature of the micronekton make the system's sampling volume (575 l) sufficient to contain 5 to 10 animals, on average, per frame during the night. These animals were primarily myctophid fish; thus, the number of myctophids per frame was consistently greater than 5 at night. A maximum of 29 myctophids were imaged in a single frame during nighttime casts. During the day, an average of 0.4 animals were imaged per frame. Images from the cameras were of sufficient resolution to identify fish and shrimp to family, and in some cases genus (Fig. 3). Myctophid fish from the genus Diaphus are particularly easy to identify because of the light organs in front of their eyes. Squid moved too rapidly for identification from still images; sections of the video were useful for confirming their identity. Measurements of squid size could be made despite the limitations in identifying them to a lower taxonomic level.

\section{Avoidance estimation}

Echosounder data from the period starting $10 \mathrm{~min}$ before and ending $10 \mathrm{~min}$ after each camera profile were averaged to provide volume scattering estimates in $1 \mathrm{~m}$ depth bins. To observe any potential avoidance of the camera system by scatterers, the volume scattering estimates prior to and immediately following the vertical profile were compared using one-tailed $t$-tests. Post-profile volume scattering was not significantly lower than pre-profile volume scattering for any of the times or locations ( $p>0.05$ for all comparisons). The volume scattering for times surrounding profiles were then compared with the average volume scattering for the entire transect using ANOVA. No significant differences in volume scattering were detected $(p>0.05$ for all comparisons).
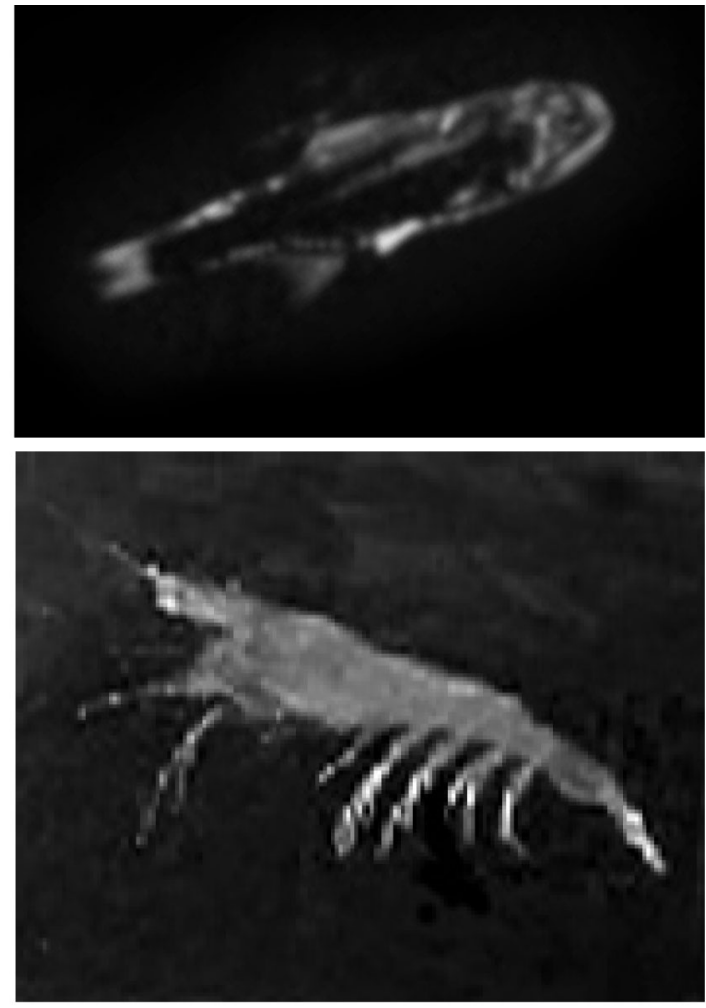

Fig. 3. Animals imaged with the micronekton camera system. In the myctophid fish (top), many of the photophores, the most conspicuous diagnostic character in this family, are visible

The taxonomic identity, size, and numeric density information obtained from the camera system were combined with measurements previously made of backscattering from individual micronekton (BenoitBird \& Au 2001) to predict the volume scattering that would be expected by an echosounder at that location. The predictions were compared with scattering measured with echosounders at 70 and $200 \mathrm{kHz}$ to look for potential avoidance by specific groups or sizes rather than the entire SSL. Predicted and actual volume scattering at $200 \mathrm{kHz}$ were significantly correlated (measured $=1.0025 \times$ predicted $+0.0295, \mathrm{r}^{2}=$ $0.68, \mathrm{p}<0.0001, \mathrm{~N}=4174$ ). A paired samples $t$-test showed no significant difference between the predicted and actual scattering at $200 \mathrm{kHz}(t=1.483, \mathrm{p}=$ $0.14, \beta=0.47$ ). There was a significant positive correlation between predicted and actual volume scattering at $70 \mathrm{kHz}$ (measured $=0.9851 \times$ predicted +1.793 , $\left.\mathrm{r}^{2}=0.63, \mathrm{p}<0.0001, \mathrm{~N}=4174\right)$. A paired samples $t$ test showed a significant difference between the predicted and actual scattering at $70 \mathrm{kHz}(t=-63.9, \mathrm{p}<$ $0.0001)$. The mean difference between the predicted and actual scattering was $-2.25 \mathrm{~dB}$; however, the slope of the regression was not significantly different from $1(\mathrm{p}=0.21)$. 


\section{Distribution of the sound-scattering layer}

The combination of echosounding to characterize large-scale pattern and profiling with the camera system for small-scale assessment permitted the taxonomic composition and numerical density of micronekton to be assessed as a function of depth, distance from the shoreline, and time. By covering the full extent of the SSL's migration both spatially and temporally, the effects of migration on taxonomic distribution, animal density, behavior, and scattering characteristics were assessed. Fig. 4 shows the vertical and onshoreoffshore distribution of the SSL and the extremes of the
Table 1. ANOVA results for the presence of the scattering layer inshore as a function of depth and distance from the shoreline

\begin{tabular}{|lrrrrc|}
\hline Source & SS & df & MS & \multicolumn{1}{c}{$F$} & $\mathrm{p}$ \\
\hline Distance from shore & 0.31 & 12 & 0.03 & 1.19 & 0.29 \\
Bottom depth & 17.11 & 57 & 0.30 & 13.62 & $<0.0001$ \\
Distance $\times$ Depth & 2.87 & 126 & 0.02 & 2.05 & $<0.0001$ \\
\hline
\end{tabular}

migration, 00:00 and 12:00 $\mathrm{h}$ local time. This represents the combined results from all replicate transects Also shown are the density estimates from both the acoustics (made through echo-energy integration) and the camera system and the composition of animals identified with the camera system.

The inshore extent of the horizontal migration was examined through a series of focused surveys. The SSL was never detected $<0.5 \mathrm{~km}$ from the shoreline or when the bottom depth was $<22.7 \mathrm{~m}$. ANOVA (Table 1) revealed that distance from shore was not a significant predictor of SSL presence; however bottom depth was, despite the interaction of these 2 terms. Only myctophid fishes were identified with the camera system in the shallowest areas.

\section{Composition of the sound-scattering layer}

The SSL was comprised of at least $80 \%$ myctophids at all times and locations (Fig. 5). ANOVA revealed a significant effect of distance from the shore on myctophid abundance and a significant interaction between time and distance from the shoreline (Table 2). A greater proportion of myctophids was found closer to the shore, though this difference decreased with time. The myctophids in the SSL ranged in size from 2.5 to $10 \mathrm{~cm}$ with an average length of $4.6 \mathrm{~cm}$. The length of myctophids was significantly affected by time and distance from the shore (Table 2, Fig. 6). Larger myctophids were found closer to the shore and appeared there earlier in the night than smaller myctophids. The density pattern of animals identified with the camera system is shown in Fig. 7. 


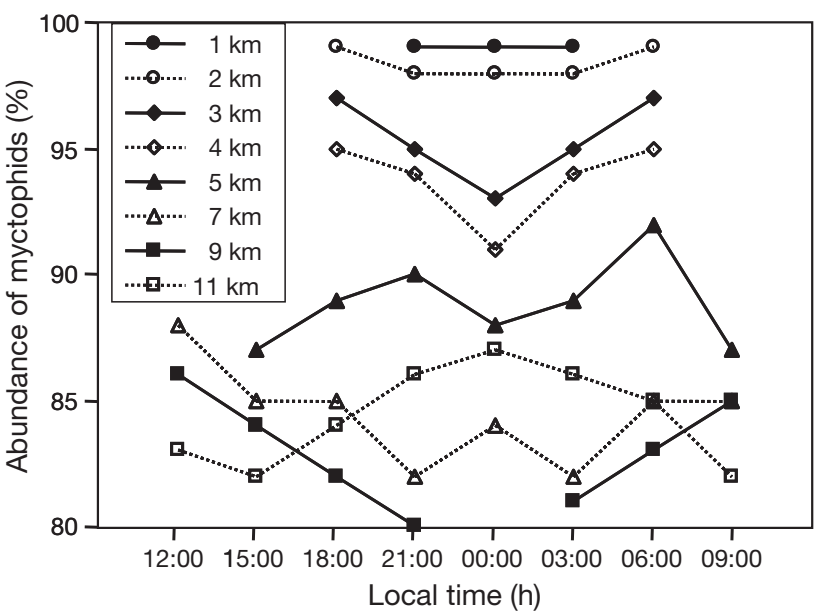

Fig. 5. Composition of the sound-scattering layer (SSL), shown as percentage of all animals identified from videos that were myctophid fishes as a function of local time for each distance from shore

\section{Detection of individual animals}

The mean target strength in $\mathrm{dB}$ measured with the split-beam echosounder is shown as a function of mean myctophid length for each alongshore transect in Fig. 8.

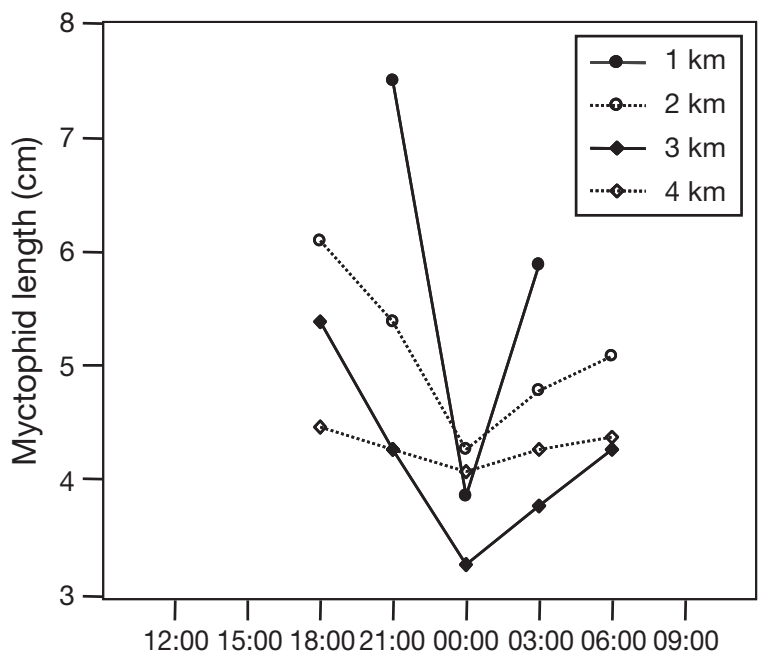

Table 2. ANOVA results for the effects of time and distance from shore on percentage of myctophids and on length of myctophids in video data

\begin{tabular}{|lrrrrc|}
\hline & SS & df & MS & $F$ & $p$ \\
\hline Percentage & & & & & \\
Time & 55.16 & 7 & 7.88 & 1.34 & 0.27 \\
Distance from shore & 2589.84 & 7 & 369.98 & 62.74 & $<0.0001$ \\
Time $\times$ Distance & 1188.7 & 32 & 37.15 & 6.30 & $<0.01$ \\
Length & & & & & \\
Time & 9.19219 & 7 & 1.31 & 2.67 & 0.03 \\
Distance from shore & 12.4783 & 7 & 1.78 & 3.62 & 0.006 \\
Time $\times$ Distance & 15.7456 & 32 & 0.49 & 0.45 & $>0.05$ \\
& & & & & \\
\hline
\end{tabular}

The mean for individual target strength was taken from the linear acoustic backscattering strength and then converted to target strength in $\mathrm{dB}$. There was a strong, linear relationship between the myctophid length measured from the video system for each transect and the average target strength (TS) of individual targets measured with the split-beam echosounder on the same transect at each frequency $\left(\mathrm{TS}_{70 \mathrm{kHz}}[\mathrm{in} \mathrm{dB}]=\right.$ $2.35 \mathrm{~L}-56.17, \mathrm{R}^{2}=0.62 ; \mathrm{TS}_{200 \mathrm{kHz}}[$ in $\mathrm{dB}]=2.03 \mathrm{~L}-$ $56.60, \mathrm{R}^{2}=0.74$; where $L$ is myctophid length in $\mathrm{cm}$ ). Multiple regression analysis revealed that length con-

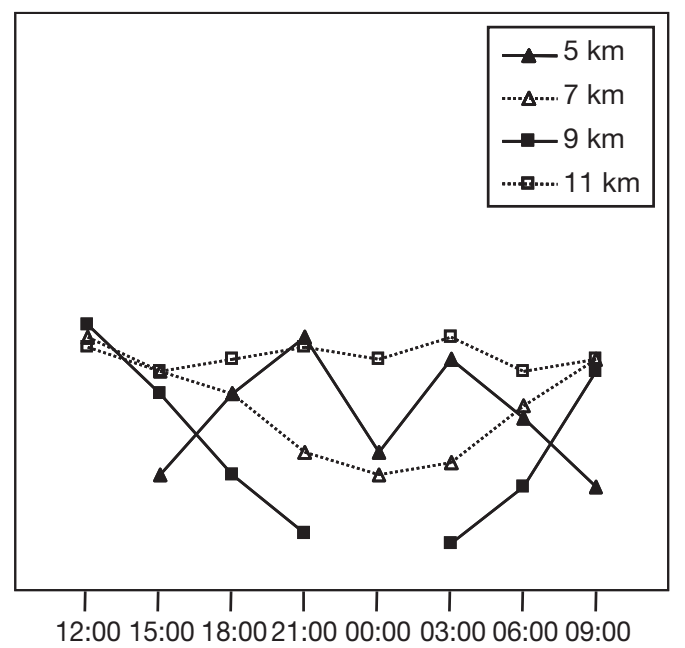

Local time (h)

Fig. 6. Mean length of myctophids in the sound-scattering layer (SSL) measured from the video system as a function of time and distance from the shoreline

Table 3. Summary of multiple regression analysis of the effects of myctophid length, percentage, and the distance of the transect from the shoreline on measured individual target strengths

\begin{tabular}{|lcccccc|}
\hline & \multicolumn{3}{c}{$70 \mathrm{kHz}$} & & \multicolumn{2}{c|}{$200 \mathrm{kHz}-$} \\
\cline { 2 - 4 } & $\mathrm{R}^{2}$ & $\mathrm{R}^{2}$ change & $\mathrm{p}$ & $\mathrm{R}^{2}$ & $\mathrm{R}^{2}$ change & $\mathrm{p}$ \\
\hline Length & 0.62 & & $<0.0001$ & 0.74 & $<0.0001$ \\
+ Myctophid percentage & 0.78 & 0.16 & $<0.0001$ & 0.99 & 0.25 & $<0.0001$ \\
+ Distance from shore & 0.79 & 0.01 & 0.12 & 0.99 & 0.00 \\
\hline
\end{tabular}



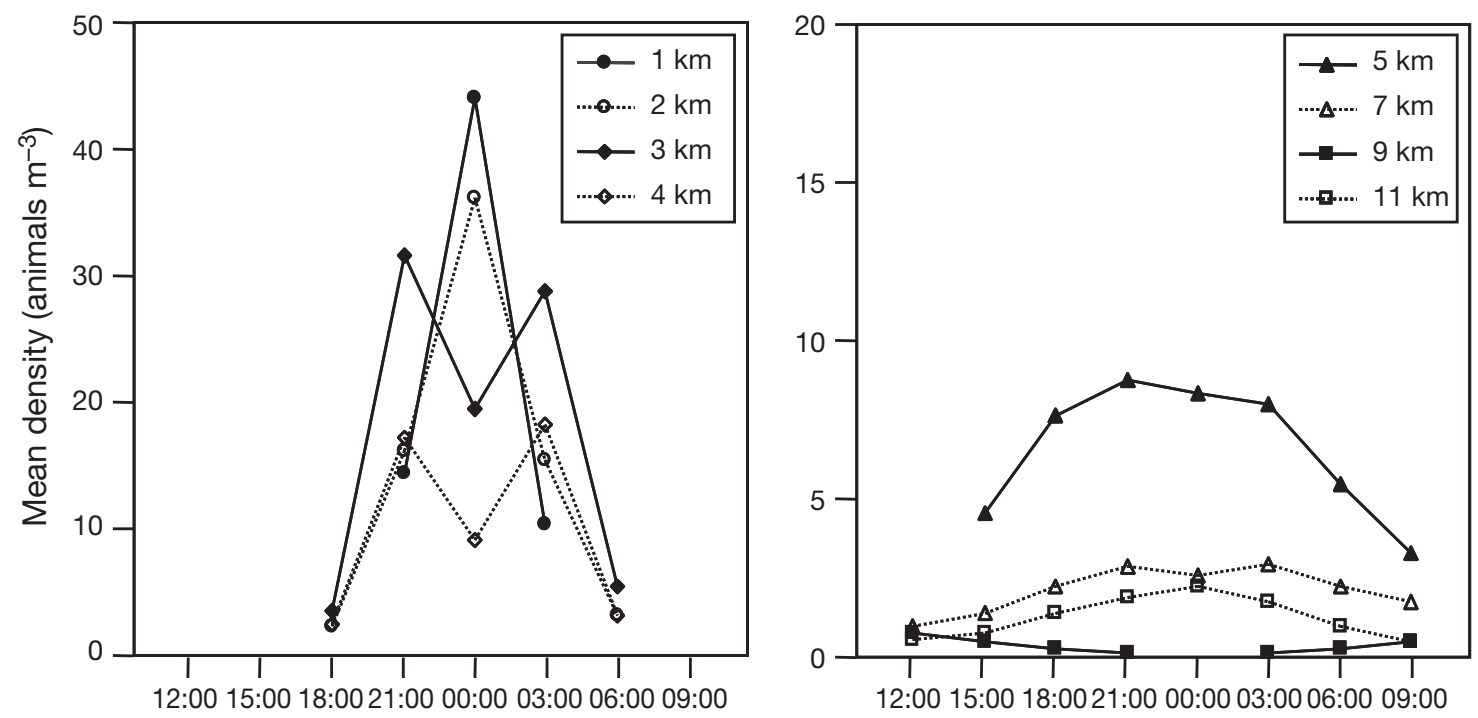

Local time (h)

Fig. 7. Mean numerical density of animals in the sound-scattering layer (SSL) measured from the video system as a function of time and distance from the shoreline. The maximum number of myctophid fish observed per image was 29

tributed significantly to the regression with target strength as did the percentage of myctophids in the identified individuals, although distance from the shoreline did not add significantly to the regression relationship (Table 3 ).

The distribution of individual target strengths reveals further the potential relationship between target strength and SSL composition. A sample histogram of

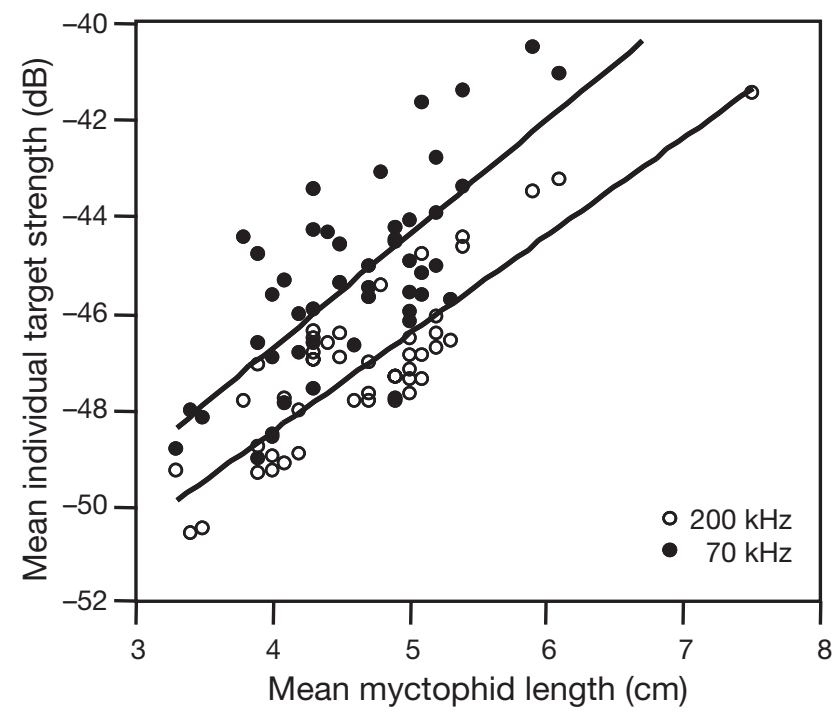

Fig. 8. Target strength of animals in the sound-scattering layer (SSL) identified individually with split-beam echosounder data plotted against the mean length of myctophids from the video system for each alongshore transect. The mean for the acoustic data was taken from the linear backscatter rather than the $\mathrm{dB}$ value. Upper regression: $70 \mathrm{kHz}$; lower regression: $200 \mathrm{kHz}$ individual targets is shown in Fig. 9. Video data from this same transect showed a composition of $88 \%$ myctophid fish with a mean length of $4.2 \mathrm{~cm}$ and $10 \%$ shrimp with a mean length of $4.8 \mathrm{~cm}$. These results compare favorably with the 2 modes of the target strength distribution, which would result from approximately $4 \mathrm{~cm}$ myctophids and a $5 \mathrm{~cm}$ shrimp. The larger

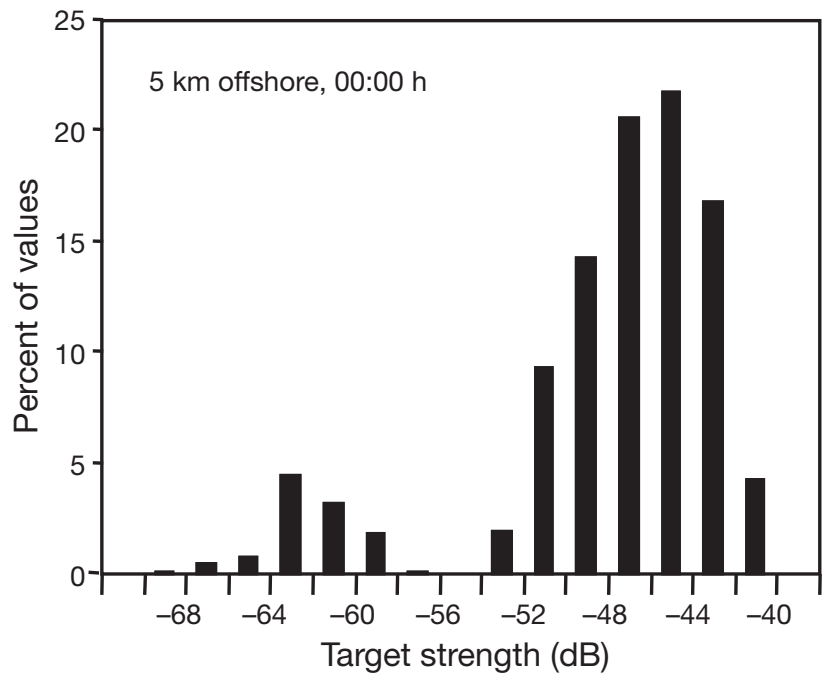

Fig. 9. Histogram of single target detections from the $200 \mathrm{kHz}$ split-beam echosounder from all depths within the soundscattering layer (SSL) at the $5 \mathrm{~km}$ offshore transect at midnight. Video showed a composition of $88 \%$ myctophid fish and $10 \%$ shrimp. The higher target strength values add up to approximately $90 \%$ of all detections with the mean corresponding to a myctophid just over $4 \mathrm{~cm}$ long. The lower values account for about $10 \%$ of all detections and would correspond to a shrimp approximately $5 \mathrm{~cm}$ in length 


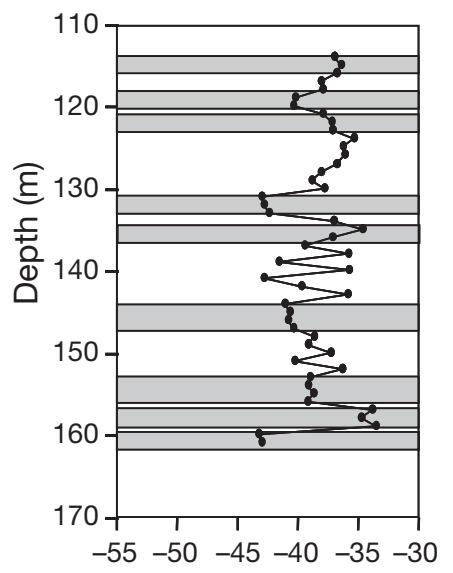

Volume backscatter $(\mathrm{dB})$

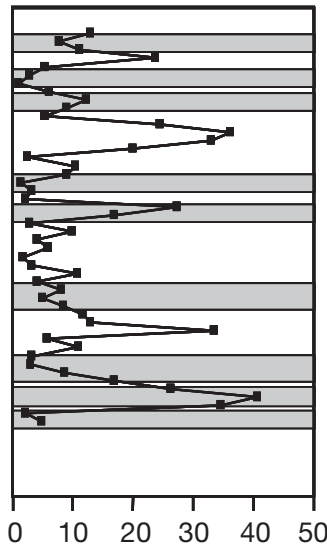

Density (animals $\mathrm{m}^{-3}$ )

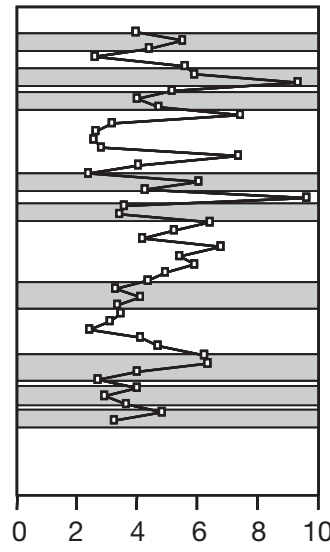

Myctophid length (cm)

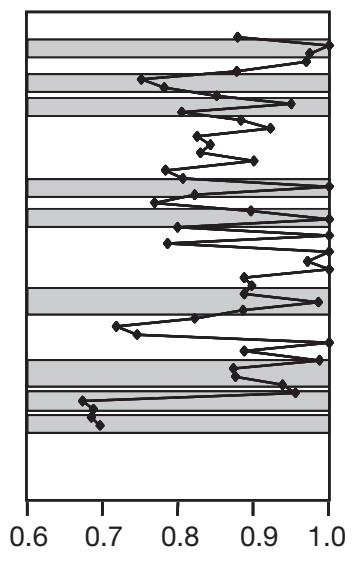

Proportion myctophids

Fig. 10. Sound-scattering layer (SSL) at 00:00 local time, $5 \mathrm{~km}$ leeward of Oahu. The 9 strata statistically identified from the $70 \mathrm{kHz}$ volume backscatter data are shown in grey. Potential factors that could contribute to the acoustic strata-camera system measurements of density, myctophid length, and proportion of myctophids - are also shown as a function of depth

Table 4. Summary of regression relationships between possible explanatory variables and the number of significant vertical strata within the sound-scattering layer. Sv: volume scattering

\begin{tabular}{|lccc|}
\hline & $\mathrm{R}^{2}$ & $\mathrm{p}$ & Slope \\
\hline Numerical density & 0.89 & $<0.001$ & + \\
Proportion myctophids & 0.43 & $<0.01$ & + \\
Myctophid length & 0.03 & $\mathrm{~ns}$ & \\
70 kHz target strength & 0.06 & $\mathrm{~ns}$ & \\
Mean S $_{\mathrm{v}}$ & 0.62 & $<0.005$ & + \\
\hline
\end{tabular}

values accounted for approximately $90 \%$ of all values, while the lower values accounted for about $10 \%$ of the values with no overlap in the middle.

\section{Vertical stratification}

Strata within the SSL were identified using the volume scattering data at $70 \mathrm{kHz}$. There was always at least 1 distinct stratum within the SSL and as many as 18 strata (1 km from shore, 00:00 h local time). The strata identified from the volume scattering data were compared with the vertical structure observed in individual target strength measurements as well as a variety of results from the camera system including numerical density, proportion myctophids, and myctophid length. An example is shown in Fig. 10. To quantify these relationships, the number of significant vertical strata was compared with each of the explanatory variables (Table 4). Because of the strong correlation between animal density and number of significant strata, the temporal and spatial patterns of both are similar (see Fig. 6).

\section{DISCUSSION}

\section{New methodology for quantifying micronekton}

Micronekton in general and mesopelagic micronekton in particular are poorly understood. Lack of data is largely due to limitations in the suite of tools available for sampling these mobile organisms. Our vessel size and the animals' habitat precluded using large midwater trawls with discrete sampling capabilities. The video camera system developed in the present study is a novel application of existing technology, and the results show that it can provide insights into mesopelagic micronekton. We found here and in previous work (Benoit-Bird \& Au 2004) that horizontal migration into shallow water habitats compresses the vertical scales of the micronekton distribution. This makes it critical to have fine vertical sampling resolution, which the combination of vessel-mounted acoustics and the profiling camera system provided.

The camera system is an effective means of groundtruthing the acoustic data, providing information on basic animal taxonomic identity, numerical density, and size. There were no significant effects of vertical profiling with the camera system on volume backscatter, suggesting that the camera system does not cause large-scale avoidance by the micronekton. Further, scattering predictions made from the camera data matched very well with the measured backscatter from the echosounders. This supports the conclusion that the animals in the field of view of the cameras are the same as those detected by the echosounders, suggesting no avoidance within $1 \mathrm{~m}$ of the camera frame. Finally, using the information from the cameras to provide animal composition and size for echo-energy integration with the acoustics provided density estimates comparable 
with those made from the cameras alone. This further supports the utility of the video camera system for ground-truthing the echosounder data.

The combination of acoustic data and the video system provides other important validation. The splitbeam echosounders are capable of measuring the target strengths of individual animals when they are not too closely spaced. The target strength of an animal is affected by its identity, size, and orientation (MacLennan \& Simmonds 1992), making it difficult to interpret these measurements without some knowledge of the target. Comparing the target strengths measured using the echosounders with the lengths measured from the camera system of the most abundant animals, myctophid fishes, showed a strong correlation. Further examination of the distribution of target strengths revealed that it was relatively easy to distinguish myctophids from other micronektonic scatterers. The distributions matched the modes of the composition observed with the cameras, showing a high target strength mode and, when a significant proportion of shrimp were present, a low target strength mode. The total proportion of the data accounted for by each node approximates the proportion of animal groups observed by the camera profiles. Further, the sizes that would be estimated from the target strengths based on the relationships measured by Benoit-Bird \& Au (2001) are extremely close to those measured directly from the camera system. This suggests that for this community, the distribution of individual target strength values can be used to determine the composition of the layer, particularly the percentage of myctophids. The length distribution of the animals can also be estimated from the individual target strengths.

\section{Micronekton migration pattern}

To understand horizontal migration behavior, it is important to understand the full cycle of migration, and which animals undertake these movements and which do not. Through focused nearshore surveys, we found midwater micronekton in extremely shallow waters as close as $0.5 \mathrm{~km}$ from the shore around midnight. It appears that the inward migration is limited by bottom depth rather than distance from the shoreline, though previous results have shown distance from the shore is more important in driving the distribution further from the shore (Benoit-Bird et al. 2001). The SSL was present only when the water was deeper than about $23 \mathrm{~m}$, regardless of how far away from shore this point occurred. The only animals detected in shallow areas were myctophid fishes.

Observations of the SSL reveal that in the middle of the night the micronektonic scatterers are actually dis- tributed in multiple, distinct layers. There are 4 layers that move inshore in addition to upwards. The shallowest layer is found closest to the shore and each subsequent layer is deeper, and further from the shore. The density of each layer decreases with distance from the shoreline, leading us to predict that a gradient in resources should exist, decreasing with increasing distance from the shoreline. Further offshore, there are 2 vertically distinct layers that are separated by nearly $100 \mathrm{~m}$ in the water column, but do not appear to move towards or away from the shore. Consequently, there is a large gap in the presence of SSLs at around $9 \mathrm{~km}$ from the shoreline at midnight. It appears that horizontal migration ceases about $9 \mathrm{~km}$ from the shore in this area. The distinct layers show differences in their composition as well as in the size of animals comprising them. The deeper layers have a greater proportion of mesopelagic shrimp than the shallower layers which contain more myctophids. In addition, the size of the myctophids in these shallower layers is consistently larger than those in further offshore, deeper layers.

During the day, there was only 1 SSL in the study area, extending from $6 \mathrm{~km}$ offshore to just past $11 \mathrm{~km}$ from the shore. The SSL's upper limit was about $400 \mathrm{~m}$ and it did not extend into waters shallower than $570 \mathrm{~m}$. Reid et al. (1991) determined the daytime upper limit of the mesopelagic boundary community with nets to be located between 350 and $400 \mathrm{~m}$ in areas with bottom depths of 400 to $700 \mathrm{~m}$, consistent with the results of this study. The SSL came to within a few meters of the bottom near the edge of the offshore slope, approximately $9 \mathrm{~km}$ from the shoreline, similar to observations from a submersible (Reid 1994).

Rough calculations of the number of animals encountered on a transect running offshore from the inshore edge of the SSL to $11 \mathrm{~km}$ offshore at midnight and midday compare favorably. Approximately 1.7 million micronektonic animals would be observed in a $1 \mathrm{~m}$ wide swath at midnight, while we estimate 1.5 million micronektonic animals would be detected in this same area at midday. Based on the composition of each layer determined from the camera system, about 1.5 million myctophids would be encountered at midnight, while about 1.3 million myctophids would be present at midday. If we partition these estimates into 2 regions - areas within $9 \mathrm{~km}$ of the shore and areas 9 to $11 \mathrm{~km}$ from the shore-the nighttime and daytime estimates within each partition remain approximately equal. This suggests that animals outside approximately $9 \mathrm{~km}$ from the shoreline in this area do not migrate towards the shore. These rough approximations along with the observations of SSL distribution and movement also suggest that the daytime layer is a merger of all 6 individual layers observed during the night. There may be distinct differences in composition 
or animal size within this larger layer, as potentially indicated by its vertical bifurcation at the nearshore edge. However, with the limited taxonomic resolution of the camera system, no differences were detected.

Within the layers that undergo movements on- and offshore, myctophids were the most abundant component. However, there were significant differences in composition and size of animals over time. In the layer closest to the shore, large myctophids were first to arrive. Until approximately midnight, the mean size of animals decreased as smaller animals reached these nearshore areas and the proportion of myctophids in the SSL decreased as other animals, particularly shrimp, migrated closer to shore. During the offshore migration, smaller animals and shrimp left first, leaving large myctophids as the last animals present nearshore and closer to the surface. This could be explained by differences in swimming speeds of component groups: myctophids have estimated sustained swimming speeds of $0.75 \mathrm{~m} \mathrm{~s}^{-1}$ (Reid 1994) with larger fish having higher rates than smaller ones (Sambilay 1990). Shrimp in this size range have sustained swimming speeds of only $0.06 \mathrm{~m} \mathrm{~s}^{-1}$, again with larger animals likely swimming faster. These differences alone would explain the observed composition patterns over time. However, these results do not fit previous modeling predictions of vertical migration. De Robertis (2002) used a simple model assuming a trade off between mortality risk and energy gain to predict the timing of migration by zooplankton. The model predicts that there should be differences in the timing of migration between size classes. Smaller animals should enter surface waters earlier and leave later than larger animals, because larger animals are more vulnerable to visual predators in well-lit surface waters. In the mesopelagic boundary layer, we found larger animals arrived first and left later. This contradiction suggests that the animals in the boundary community are under different constraints. Perhaps energy acquisition is more difficult in these relatively nutrient poor subtropical waters, changing the tradeoff. Alternatively, visual predation may not be as prevalent or may not be as strongly graded with depth because of the water clarity and relatively deeper penetration of light.

The model of De Robertis (2002) did not take travel time into account when considering differences in migration timing. Travel time between habitats in the extensive migrations observed is likely very important. The extreme swims undertaken by these animals may make it impossible for smaller animals to meet their ideal timing because of the limits in their swimming abilities. With their estimated swimming speeds sustained, an average sized myctophid would take just under $4 \mathrm{~h}$ to complete a $10 \mathrm{~km}$ migration, while a shrimp could not complete the migration within a day.
Shrimp simply do not have enough time to reach the nearshore habitat from deep water. Smaller fish, swimming slower, would need to use a different migration tactic from larger fish to avoid visual predation, despite the potentially lower risk of being seen. Smaller individuals would have to leave much earlier than larger fish to reach safer, deep waters offshore before dawn. Visual predation risk likely still plays an important role in structuring this migration, but through the physical swimming limitations of the animals rather than simply their risk of being seen.

Within the various strata, there was significant vertical structure in acoustic backscatter, as also observed in Benoit-Bird \& Au (2003c). The type of scatterer, their size, their numerical density, and their orientation affects backscatter. Using a combination of individual target strength and various measures from the camera system, we explored the potential causes of backscatter strata within the individual SSLs. Vertical strata were most strongly related to changes in the density of animals with depth, with higher densities correlated with stronger backscatter. The depth of some individual strata appeared to be related to the proportion of myctophids, particularly the deepest stratum in each layer, which showed a greater proportion of shrimp than other areas. The number of strata was also highly correlated with the overall density of micronektonic animals, with higher density areas having a greater number of strata. The proportion of myctophids and the mean volume backscatter were also correlated with the number of strata; however, the length of myctophids and the individual target strength measurements were not.

The stratification in vertical space and the separation of layers with distance from shore suggest resource partitioning in this vertically compressed habitat. A large number of individuals are utilizing this narrow border between land and the open ocean, within a constricted depth range, and avoiding both the surface and seafloor. This differential use of habitat is very dynamic, so while animals may occupy the same depth and location, they do so at different times of the night. This suggests a fine-scale use of the habitat, which has been observed in other low-latitude mesopelagic micronekton assemblages (Hopkins \& Gartner 1992, Hopkins \& Sutton 1998). The habitat dimension added by directed movement by the micronekton towards and away from shore increases the possibility of habitat separation. The real stratification is probably even greater than measured in this study because of our limited taxonomic resolution in this diverse, low-latitude assemblage.

Fine scale separation of habitat use could reduce the competition between individuals in these relatively dense aggregations. The relative environmental stabil- 
ity of low-latitude oceanic ecosystems has led to the prediction that niche parameters would be primarily determined by biological parameters (McGowan \& Walker 1979), which could lead to strong resource partitioning in spatially-packed species complexes (Domanski 1984, Hopkins \& Gartner 1992). The resource that the animals are competing for could be food, space, or light field. There is a lack of feeding and diet data for boundary community animals, making it impossible to assess this niche parameter. The results show inter- and intra-specific (size) separation of animals in space, both with depth and distance from the coastline, which is likely correlated with food availability as gradients in potential prey have been observed in both dimensions (Leis 1982, Hassett \& Boehlert 1999). The vertical separation could also lead to large differences in the light field experienced by animals, and consequently in their predation risk from visual predators (see Enright \& Honegger 1977, Ohman 1988, Lampert 1989). Based on the average light transmission characteristics of the water column during the surveys, a change in water depth of $10 \mathrm{~m}$ would result in a decrease in light available to a visual predator of about $25 \%$. The balance of these pressures, feeding and predation avoidance, are likely different for different individuals, leading to a variety of 'ideal' habits which could lead to the stratification observed.

The present study shows that animals in the mesopelagic boundary layer make horizontal migrations of at least $5.5 \mathrm{~km}$ (possibly up to $10 \mathrm{~km}$ ) inshore each night. A round trip migration of at least $11 \mathrm{~km}$ must be costly, both in time from other activities and energy. This indicates that there must be a substantial benefit to horizontal migration, though the feeding advantages of this impressive movement have not been investigated. Reid et al. (1991) suggested that the animals in this boundary region are well-adapted resident populations rather than oceanic stragglers, but raised questions about how they maintained their position within such a narrow habitat and what allowed them to successfully exploit this habitat. We suggest that horizontal migration plays a role in habitat expansion, allowing mesopelagic animals to use habitats that are much shallower than typical for them at night, while remaining in deep, dark areas during the day. In addition, horizontal migration provides a mechanism for animals to maintain their position in this narrow zone, moving them predictably over the island's slopes daily. The dynamics of this migration are much greater than previously described and suggest that, despite the constrained nature of the habitat, there is strong partitioning among size classes and taxonomic groups in space and time as a result of differential migration. During the day, however, there is little evidence of partitioning of habitat, suggesting a reduction of competition relative to nighttime. We suggest that rather than simply being described by composition, the mesopelagic boundary community should be defined by this striking diel migration behavior that appears to have allowed it to successfully radiate into the nearshore habitat.

Acknowledgements. We thank M. McManus, R. Letelier, and D. Luther for lending us equipment. A. Ashe and B. McLaughlin provided assistance with equipment setup. C. Bird provided customized software. A. De Robertis and A. Lavery provided helpful comments on the manuscript. This work was funded in part by the Office of Naval Research, Marine Mammal Science and Technology Program, ONR Award Number: N00014-02-1-0968, as well as by the National Oceanic and Atmospheric Administration, Project R/FM-7, which is sponsored by the University of Hawaii Sea Grant College Program, SOEST, under the institutional Grant No. NA16RG2254 from NOAA Office of Sea Grant, Department of Commerce. The views expressed herein are those of the authors and do not necessarily reflect the views of NOAA or any of its subagencies. UNIHI-SEAGRANT-JC-05-17.

\section{LITERATURE CITED}

Benoit-Bird KJ, Au WWL (2001) Target strength measurements of animals from the Hawaiian mesopelagic boundary community. J Acoust Soc Am 110:812-819

Benoit-Bird KJ, Au WWL (2003a) Prey dynamics affect foraging by a pelagic predator (Stenella longirostris) over a range of spatial and temporal scales. Behav Ecol Sociobiol 53:364-373

Benoit-Bird KJ, Au WWL (2003b) Echo strength and density structure of Hawaiian mesopelagic boundary community patches. J Acoust Soc Am 114:1888-1897

Benoit-Bird KJ, Au WWL (2003c) Spatial dynamics of a nearshore micronekton sound-scattering layer. ICES J Mar Sci 60:899-913

Benoit-Bird KJ, Au WWL (2004) Diel migration dynamics of an island-associated sound-scattering layer. Deep-Sea Res I 51:707-719

Benoit-Bird KJ, Au WWL, Brainard RE, Lammers MO (2001) Diel horizontal migration of the Hawaiian mesopelagic boundary community observed acoustically. Mar Ecol Prog Ser 217:1-14

Boehlert GW, Genin A (1987) A review of the effects of seamounts on biological processes. Geophys Monogra 43: 319-334

Boehlert GW, Watson W, Sun LC (1992) Horizontal and vertical distributions of larval fishes around an isolated oceanic island in the tropical Pacific. Deep-Sea Res 39: $439-466$

Clarke T (1973) Some aspects of the ecology of lanternfishes in the Pacific Ocean near Hawaii. Fish Bull 71:401-434

Comeau S, Boisclair D (1998) Day-to-day variation in fish horizontal migration and its potential consequence on estimates of trophic interactions in lakes. Fish Res 35:75-81

De Meester L (1993) Genotype, fish-mediated chemical, and phototactic behavior in Daphnia magna. Ecol 74: $1467-1474$

De Robertis A (2002) Size-dependent visual predation risk and the timing of vertical migration: an optimization model. Limnol Oceanogr 47:925-933 
Domanski P (1984) The diel migrations and distribution within a mesopelagic community in the North East Atlantic. 8. A multivariate analysis of community structure. Prog Oceanogr 13:491-511

Enright JT, Honegger HW (1977) Diurnal vertical migration: adaptive significance and timing. Part 2. Test of the model: details of timing. Limnol Oceanogr 22:873-886

Foote KG, Vestnes G, Maclennan DN, Simmonds EJ (1987) Calibration of acoustic instruments for fish density information: a practical guide. International Council for the Exploration of the Sea Cooperative Research Report 144

Gjøsaeter J (1984) Mesopelagic fish, a large potential resource in the Arabian Sea. Deep-Sea Res 31:1019-1035

Haight WR, Parrish JD, Hayes TA (1993) Feeding ecology of deepwater lutjanid snappers at Penguin Bank, Hawaii. Trans Am Fish Soc 122:328-347

Hassett RP, Boehlert GW (1999) Spatial and temporal distributions of copepods to leeward and windward of Oahu, Hawaiian Archipelago. Mar Biol 134:571-584

He X, Bigelow KA, Boggs CH (1997) Cluster analysis of longline sets and fishing strategies within the Hawaii-based fishery. Fish Res 31:147-158

Hopkins TL, Gartner JVJ (1992) Resource-partitioning and predation impact of a low-latitude myctophid community. Mar Biol 114:185-197

Hopkins TL, Sutton TT (1998) Midwater fishes and shrimps as competitors and resource partitioning in low latitude oligotrophic ecosystems. Mar Ecol Prog Ser 164:37-45

Hulley PA (1992) Upper-slope distributions of oceanic lanternfishes. Mar Biol 114:365-383

Kawaguchi K, Shimuzu H (1978) Taxonomy and distribution of the lanternfishes, genus Diaphus, in the western Pacific, eastern Indian Oceans and the Southeast Asian Seas. Bull Ocean Res Inst Univ Tokyo 10:1-145

Kubota T, lizka K, Okutani T (1982) Some biological aspects of Abralia andamanica from Suruga Bay, Japan. J Fac Mar Sci Tech 40:150-159

Lampert W (1989) The adaptive significance of diel vertical migration of zooplankton. Funct Ecol 3:21-27

Leis JM (1982) Nearshore distributional gradients of larval fish and planktonic crustaceans in Hawaii. Mar Biol 72: 89-97

Lindstrom M (1991) Factors affecting the horizontal migration of the amphipod Pontoporeia affinis Lindstrom. 1. Recording method and response to water currents. J Exp Mar Biol Ecol 150:149-162

MacLennan DN, Simmonds EJ (1992) Fisheries acoustics. Chapman \& Hall, New York

Mauchline J, Gordon JDM (1991) Oceanic pelagic prey of benthopelagic fish in the benthic boundary layer of a marginal oceanic region. Mar Ecol Prog Ser 74:109-115

May JL, Blaber SJM (1989) Benthic and pelagic fish biomass

Editorial responsibility: Otto Kinne (Editor-in-Chief), Oldendorf/Luhe, Germany of the upper continental slope off eastern Tasmania. Mar Biol 101:11-25

McGowan JA, Walker PW (1979) Structure in the copepod community of the North Pacific Central Gyre. Ecol Monogr 49:195-226

Norris KS, Dohl TP (1980) Behavior of the Hawaiian spinner dolphin, Stenella longirostris. Fish Bull 77:821-849

Ohman MD (1988) Behavioral responses of zooplankton to predation. Bull Mar Sci 43:530-550

Omori M, Ohta S (1981) The use of underwater camera in studies of vertical distribution and swimming behaviour of a sergestid shrimp, Sergia lucens. J Plankton Res 3: 107-121

Parin NV, Prut'ko VG (1985) The thalassial mesobenthopelagic icthyocoene above the equator seamount in the western tropical Indian Ocean. Oceanol 25:781-783

Rasmussen OI, Giske J (1994) Life history parameters and vertical distribution of Maurolicus muelleri in Masfjorden in summer. Mar Biol 120:649-664

Raymond EL, Widder EA (2005) Eye-in-the-sea: a platform for unobstrusive in-situ observations of deep-sea nekton. Am Soc Limnol Oceanogr 2005 Aquatic Sciences Meeting, Feb 20-25, 2005, Salt Lake City, UT. Am Soc Limnol Oceanogr, Waco, TX

Reid SB (1994) Spatial structure of the mesopelagic fish community in the Hawaiian boundary region. PhD Dissertation, University of Hawaii, Honolulu, HI

Reid SB, Hirota J, Young RE, Hallacher LE (1991) Mesopelagic-boundary community in Hawaii: micronekton at the interface between neritic and oceanic ecosystems. Mar Biol 109:427-440

Sambilay VC Jr (1990) Interrelationships between swimming speed, caudal fin aspect ratio and body length of fishes. Fishbyte 83:16-20

Sasaki M (1914) Observations on Hotaru-ika, Watasenia scintillans. J Coll Agric, Hokkaido Univ 6:75-107

Sawada K, Furusawa M, Williamson NJ (1993) Conditions for the precise measurement of fish target strength in situ. Fish Sci 20:15-21

Skillman RA (1998) Central Pacific swordfish, Xiphias gladius, fishery development, biology, and research. NOAA Tech Rep 142, NMFS

Stone R (1998) First glimpse at hidden life of seals. Science 279:657

Suh HL, Yu OH (1996) Diel horizontal migration of planktonic copepods in the surf zone of Yongil Bay, Korea. J Korean Fish Soc 29:527-536

Webb P, Wooldridge TH (1990) Diel horizontal migration of Mesopodopsis slabberi (Crustacea: Mysidacea) in Algoa Bay, Southern Africa. Mar Ecol Prog Ser 62:73-78

White MG (1998) Horizontal distribution of pelagic zooplankton in relation to predation gradients. Ecography 21:44-62

Submitted: March 6, 2006; Accepted: June 26, 2006

Proofs received from author(s): July 29, 2006 